\title{
Rethinking the role of Higher Education
}

\author{
Santiago Mengual-Andrés ${ }^{*}$ \\ Departamento de Educación Comparada e Historia de la Educación, Universidad de Valencia, Spain \\ \{santiago.mengual@uv.es\}
}

Received on 2 October 2012; revised on 15 October 2012; accepted on 30 October 2012; published on 15 January 2013

DOI: $10.7821 /$ naer.2.1.1-2

\begin{abstract}
The market has to change as our current society becomes increasingly diverse and so do workers' competences, which are now more and more cross-disciplinary. New training models have appeared seeking to meet such market and society needs. This editorial reflects on the pressing need to redefine university education and the accreditation processes in non-formal education.
\end{abstract}

KEYWORDS: EDUCATION, UNIVERSITY, GLOBALIZATION, OPEN EDUCATION, ACCREDITATION, POLITICS

\section{THE NECESSARY REDEFINITION OF HIGHER EDUCATION}

A phenomenon that affects both Europe and the developed world as a whole is compromising the proper operation of the global economic post-industrial model. Recent events have highlighted the fragility of supranational relations as well as the difficulties that national and international organizations have to face when it comes to provide global and uniform solutions that can alleviate some of the consequences derived from the current economic crisis. This situation has clearly shown not only the weakness of countries but also their strong dependence on markets. The growing need to respond to the market (as a result of the evolution of classical liberalism) has led to the deterioration of the social welfare state and, consequently, to a decrease in the protection of social rights by the State, including the universal individual right to receive education. This has become evident in the Spanish context, where budget cuts in public education have increased while the support to private education is being guaranteed by law.

Undoubtedly, the changes experienced in today's world as a result of globalization inevitably imply a collective

\footnotetext{
*To whom correspondence should be addressed:

Universidad de Valencia

Facultad de Filosofía y Ciencias de la Educación

Departamento de Educación Comparada e Historia de la Educación

C/ Avda. Blasco Ibáñez, 30

46010 Valencia

Spain
}

reflection by all the actors involved in the world of education. Neither political scientists nor politicians, heads of state, economists, large multinational corporation managers or teachers/lecturers should be left aside when reflecting on the educational crisis that our information and communication society is going through. The neoliberal policies that Spain is contemplating offer a very particular vision about what and how education should be. While OECD or UNESCO highlight the need for state investment in Education as the best way to support the welfare state, improve R\&D competitiveness and generate human capital, the privatization and "rationalization" of public expenditure undertaken by the Spanish Government is having far-reaching implications. The quality of education and its guarantees are indeed closely associated with the investment made in education. Diversity requires even more attention, and managing overcrowded classrooms without any homogeneity is certainly not an easy task.

An illustration of this approach can be found in one of the world's largest market-oriented educational systems -the U.S.- where a celebrity like Bill Gates has recently announced the intention to invest in education through his foundations with the aim of reducing public deficit and improving current competitiveness levels.

In this context, societies should ask themselves what companies actually expect from their future employees. At a historical moment in which university fees are the highest ever and graduate training has become exceptional, universities are faced with a dilemma which they still do not know how to resolve. On the one hand, classical higher education prepares future graduates for the working world but, on the other hand, companies need professionals with skills that are far from those taught in the university context, at least in Spain. For this reason, the range of new professions keeps growing before our eyes: content curators, community managers, traffickers, big data specialists and, specially, leinners, citizens that have learned to adapt to the digital world, moving on quickly and becoming competent in some e-skills that they had never learned in formal higher education.

It is necessary to look ahead of time in the education of our students, something which some institutions are already doing by offering first the MBA, then the 
Executive MBA and finally the Global Executive MBA. Only some can access these excellent programs; maybe not the best candidates but rather the ones that can pay for these studies. However, these are not the only ways for students to acquire new competences in the $21^{\text {st }}$ century. One of the most interesting aspects about the Internet is its decentralization, its immateriality, the fact that it breaks the concepts of time and space. Internet has grown so much that it cannot possibly be measured. Its contribution to human knowledge and society is undeniable and, as such, it has given rise to new scenarios for formal and informal training and learning and, above all, to new skill acquisition processes.

E-learning and B-learning appeared in the past decade as online training methods that led to the creation of excellent universities based on this model, such as the Open University and the Universitat Oberta de Catalunya. Education is not limited to the physical setting of a classroom. Virtual classrooms offer possibilities that conventional education could never provide; a form of education that is closer to the digital generation as well as to graduates' needs.

The expansion of online universities has been followed by the proliferation of OpenCourseWare, institutional academic content repositories that prestigious universities such as MIT have joined with remarkable initiative. The educational content imparted in formal education is no longer exclusively available to registered students. Anyone can learn American History using the same material as students enrolled at MIT.

At the same time, large companies such as Apple have found a business model in this initiative. They offer an application called iTunesU which allows educational institutions to create their website and host their content for free so that application users may freely subscribe to the whole course or institutional content.

It comes as no surprise given the wide offer of contents and courses that MOOCs (Massive Open Online Courses) started to appear as the new way of learning: open courses, free of charge, distributed, and creating a learning network; the ultimate form of Life Long Learning: Learn what you want and what you need, whenever you wish. MOOCs are no longer mere repositories, as in the case of OCW, and they add interactivity to the content. A link between learners and teachers, and ultimately a learning process, is created.

Coursera, edX or Udacity stand out as some of the most popular examples of MOOCs. In fact, these initiatives are starting to be used by institutions such as Antioch University which recognize some of these courses as part of their curriculum.

The present situation requires a thorough analysis about the current situation of higher education. Universities, which are supposed to guarantee the transmission of culture, innovation and research, must inevitably adapt to this changing world. The immutable nature of most training programmes leads to a disconnection between work-related needs and university training. This is why numerous graduates are forced to complete their training with extra-academic work placements or non-formal education programmes which enable them to acquire the necessary skills to succeed in the global marketplace.

It is necessary for universities to take an active role in an area of special complexity, namely: the formal accreditation and validation of informal learning. A simple question can exemplify the need for further action. Why can students not validate an MIT research methodology course as part of their formal university training? In our opinion, the rigidity of administrative structures and academic interests is hindering the progress of higher education to a great extent, which forces students to seek more flexible ways of training and, particularly, of acquiring new skills. The formal accreditation of knowledge is as important as learning the competences required to face the $21^{\text {st }}$ century reality.

Should Higher Education consider a change of direction then? In our view, the university should definitely make an effort to assume a new role -that of an "authorizer"establishing mechanisms that can generate synergies between non-formal learning and its necessary formal accreditation.

In a world where the wide variety of options offered by technology make it possible for people to develop a custom-made training plan oriented towards specific jobs that universities are not prepared for, our role as educators is, without a doubt, working to integrate these new learning realities into the formal educational life of every citizen.

Prof. Dr. Santiago Mengual Andrés Executive Editor 